\title{
ANÁLISE NUMÉRICA DA INFLUÊNCIA DE DEFEITOS INTERNOS NA FALHA DE PRODUTOS OBTIDOS POR LAMINAÇÃO TRANSVERSAL COM CUNHA
}

\author{
G. H. Judice ${ }^{1}$, S. T. Button ${ }^{2}$
}

${ }^{1}$ Departamento de Engenharia de Materiais, Faculdade de Engenharia Mecânica na Universidade Estadual de Campinas (gustavoghj@hotmail.br)

${ }^{2}$ Departamento de Engenharia de Materiais, Faculdade de Engenharia Mecânica na Universidade Estadual de Campinas (sergio1@fem.unicamp.br)

Resumo. O processo de conformação denominado Laminação Transversal com Cunha, também conhecida como Cross Wedge Rolling, tem se destacado na indústria pela sua flexibilidade, produtividade e economia de material, porém pode apresentar o problema do defeito interno que inviabiliza a utilização dos seus produtos. Esse estudo tende a demonstrar através de simulações por métodos numéricos do processo de laminação transversal com cunha, como as falhas internas de um material - vazios e inclusões - vêm a evoluírem para defeitos de grandes proporções, assim se desenvolveu diferentes modelos de elementos finitos no software comercial Abaqus ${ }^{\circledR}$ versão 6.9-2. Foram simulados modelos bidimensionais com vazios internos de diferentes tamanhos e disposições. Posteriormente, foram simulados modelos com inclusões circulares, quadráticas e triangulares, a fim de avaliar o que essas características influenciam no processo. E por fim, foi simulado um modelo utilizando o recurso de caracterização de porosidade do aço, gerando uma representação dos locais de nucleação e coalescência de poros. Os modelos com vazios apresentaram elevados valores de tensão junto a suas circunferências, sendo que esses vazios tenderam a fechar durante a deformação, já os modelos com inclusões apresentaram também altos valores de tensão ao seu redor com uma tendência à formação de fissuras e o modelo com propriedades de porosidade confirmou que há a tendência de nucleação e coalescência de vazios na região central do tarugo.

Palavras Chave: Laminação Transversal com Cunha, defeito interno, elementos finitos.

\section{INTRODUÇÃO}

A Laminação Transversal com Cunha (LTC) é um processo de conformação que tem se destacado e está em constante desenvolvimento devido às suas vantagens [16]. Esse processo é caracterizado pela deformação plástica de uma barra devido a ação de ferramentas em formato de cunha que se movem tangencialmente uma em relação à outra [11].

O processo LTC apresenta três principais grupos característicos de defeitos que são a formação de cavidades e poros, defeitos de superfície e seções com geometria diferente da esperada. $\mathrm{O}$ defeito que apresenta maior ocorrência nesse processo é a formação de cavidades 
ou vazios no interior dos produtos como representado na Figura 1. Esse tipo de defeito também é conhecido como "efeito Mannesmann", tendo grande importância no processo já que pode se estender por toda a região da peça acarretando em perda de resistência do produto, podendo levar a sua ruptura $[8,9]$.

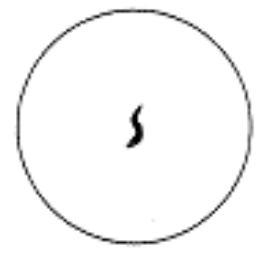

(a)

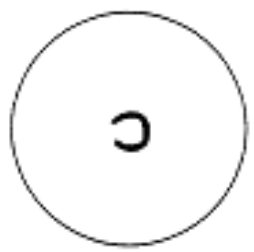

(b)

Figura 1: Vazios internos em seções transversais, onde (a) é oriundo de processos com dois rolos ou ferramentas planas e (b) de ferramentas com três rolos [8].

Segundo Li et al. [10] as causas para a formação desses defeitos internos podem ser atribuídas a forte tensão de tração na parte central do corpo de prova, a tensão de cisalhamento excessiva causada pela ação das ferramentas de conformação e pela fadiga de baixo ciclo que se desenvolve durante o processo de laminação.

A modelagem numérica através do Método de Elementos Finitos (MEF) de defeitos internos tem ganhado destaque sobre métodos experimentais em vários estudos, sendo utilizados diversos softwares.

Ao modelar numericamente um processo deve-se determinar a densidade da malha de elementos finitos a fim de investigar a sua influência nos resultados, principalmente ao modelar descontinuidades geométricas [1].

Um modelo que representa defeitos internos de materiais como inclusões e poros, é normalmente modelado apresentando as dimensões destes defeitos bem maiores que o real a fim de economizar em tempo de simulação, podendo ser adotados com propriedades hipotéticas quando se objetiva analisar o material matriz [7].

Ao estudar o campo de tensão ao redor de inclusões através do MEF, também é possível obter resultados quanto a posição e tamanho de fissuras formadas em torno dessas inclusões assim como a sua forma final, ressaltando que as inclusões podem apresentar diferentes formas, como circulares, quadráticas e triangulares [17]. Em casos mais específicos, uma análise micrográfica do material utilizado deve ser realizada a fim de determinar os formatos adequados das inclusões [5].

Ao modelar diferentes formas de inclusões com o objetivo de avaliar o comportamento do material ao redor dessas, deve-se manter um mesmo volume entre as formas de inclusões para que não ocorram alterações no campo de tensão devido a diferença de frações de volume [5].

Há ainda a possibilidade de modelar a porosidade do material de forma geral, sem modelar vazio por vazio, utilizando recursos específicos do software. Como o início da deformação plástica de metais porosos é governada por critérios de escoamento que são fundamentalmente diferentes das que vigoram em materiais completamente densos, os parâmetros da modelagem de porosidade devem ser inseridos cuidadosamente por provocarem mudanças significativas nos resultados das tensões volumétricas [3]. 
Ao modelar o processo LTC por meio do MEF, existem alguns aspectos que devem ser respeitados. O modelo deve ser confeccionado pela caracterização da interface de deslizamento entre o tarugo a ser conformado e a ferramenta através do MEF explícitodinâmico.

O modelo LTC deve consistir de uma peça cilíndrica (tarugo) que é delimitada por duas ferramentas planas com cunha, paralelas entre si e equidistantes em relação ao tarugo. Os graus de liberdade nodais das ferramentas de conformação devem ser restringidos em ambas as direções: vertical (direção y) e fora-de-plano (direção z), tendo os movimentos confinados à direção $\mathrm{x}$. Por último, restrições adicionais de deslocamento $(\mathrm{x}, \mathrm{y}, \mathrm{z})$ também podem ser aplicados aos nós ao longo da linha central do tarugo para o fixar até que ocorra o contato com as ferramentas [6].

Ao estudar os defeitos internos do processo LTC, as regiões das ferramentas responsáveis pelo início da deformação apresentam os resultados mais influentes, pois o início de vazios é conhecido por ocorrer nessas regiões, sendo a deformação plástica efetiva o melhor critério para a predição dessa falha interna [10].

Battin [2] conclui em seu estudo que o software Abaqus apresenta uma condição favorável na sua utilização por promover multi-soluções para a indústria, principalmente na área da conformação, o que o torna um potencial candidato, a um custo barato, para substituir pacotes específicos de softwares de conformação, já que esse software permite o controle total sobre a definição de dados de tensão-deformação junto a processos térmicos, em que esses dados podem ser facilmente incorporados na análise.

Fenômenos de transferência de calor como condução térmica, convecção e a radiação podem ser modelados de forma eficiente, tornando o software Abaqus uma ferramenta confiável na simulação de processos simultâneos de deslocamento e temperatura. Battin [2] relata ainda que o software Abaqus também apresenta a capacidade de adaptar a malha adotada em um modelo de elementos finitos, tornando-o uma ferramenta robusta e poderosa.

\section{MATERIAIS E MÉTODOS}

O uso de recursos numéricos foi utilizado para simular como falhas representadas por vazios e inclusões se desenvolvem ao longo da etapa inicial de um processo de Laminação Transversal com Cunha, utilizando os conceitos de Elementos Finitos. Para tanto, utilizou-se o software Abaqus para a modelagem digital de um modelo compatível ao observado no processo real e para a análise do comportamento dessas falhas internas.

Foram definidos dois materiais na idealização do processo LTC, sendo as ferramentas representadas pelas propriedades do aço ferramenta H11 e o tarugo a ser laminado foi representado pelo aço microligado $38 \mathrm{MnSiVS5}$.

As ferramentas foram consideradas como sendo rígidas a fim de gastar um menor tempo de simulação, tendo apenas o valor da capacidade térmica $(420 \mathrm{KJ} / \mathrm{K})$ necessário para a modelagem.

Já a modelagem das propriedades do tarugo foram definidas como sendo do aço microligado 38MnSiVS5, que tem sua composição química representada na Tabela 1. 
Tabela 1: Composição química (\% em peso) do aço microligado [14].

\begin{tabular}{cccccccccccc}
\hline $\mathbf{C}$ & $\mathbf{M n}$ & $\mathbf{S i}$ & $\mathbf{P}$ & $\mathbf{S}$ & $\mathbf{C r}$ & $\mathbf{N i}$ & $\mathbf{M o}$ & $\mathbf{V}$ & $\mathbf{C u}$ & $\mathbf{A l}$ & $\mathbf{N}$ \\
\hline 0.37 & 1.41 & 0.60 & 0.014 & 0.055 & 0.11 & 0.10 & 0.02 & 0.09 & 0.04 & 0.011 & 0.0157 \\
\hline
\end{tabular}

Em seguida, a primeira etapa de deformação processo em si de LTC foi modelada, que é a região de fendilhamento, pois essa é a região na qual as primeiras deformações ocorrem e segundo Li et al. [10], por essa região (assim como a região guia) ser responsável pelo início da formação de vazios.

O modelamento do processo foi bidimensional para economizar o tempo de simulação. O tarugo foi modelado apresentando uma seção transversal circular, com diâmetro de $24 \mathrm{~mm}$ e as ferramentas foram modeladas como sendo segmentos de retas (Figura 2).

A escolha das dimensões do tarugo e das ferramentas, assim como a montagem inicial do processo LTC, representado pela Figura 2, foram definidos seguindo os parâmetros do processo LTC existente no Laboratório de Conformação Mecânica da Faculdade de Engenharia Mecânica da Universidade Estadual de Campinas.

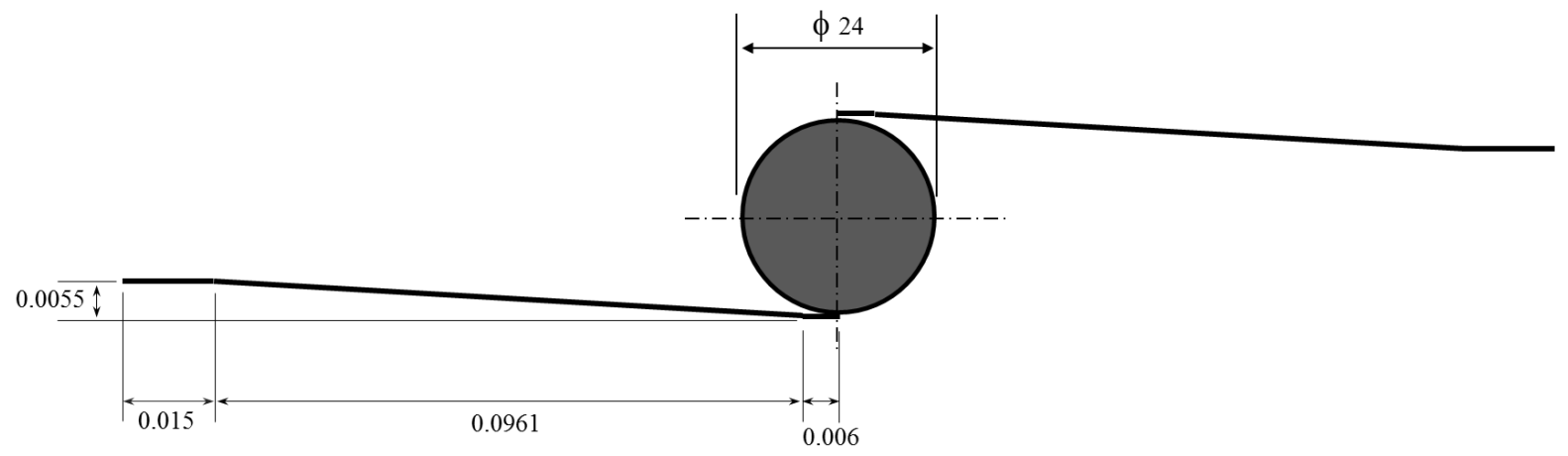

Figura 2: Esquema geral da montagem bidimensional do processo de LTC com as dimensões destacadas e em milímetros.

Modelou-se o processo LTC como sendo explícito e dinâmico, e apresentando propriedades de troca de calor. O tempo de operação do processo foi definido como atuante até que o final das regiões das ferramentas passassem pelo tarugo, num intervalo de tempo próximo de 1,188 segundos.

As ferramentas foram consideradas como sendo isotérmicas por serem rígidas. Porém as mesmas ainda participam da simulação como corpos que apresentam energia térmica, assim, quando as ferramentas e o tarugo estão em contato, ocorre transferência térmica. Além disso, quando se inicia o processo, ocorre a geração de energia devido ao atrito, sendo essa energia dissipada em calor, com $50 \%$ desse calor transmitido ao tarugo.

Também foi modelada a radiação de calor do tarugo para o meio ambiente de forma uniforme e com o meio ambiente apresentando temperatura igual a $27^{\circ} \mathrm{C}$.

$\mathrm{O}$ atrito existente entre as ferramentas e o tarugo, responsável por gerar o movimento de rotação do tarugo, foi modelado segundo o método do fator de atrito constante com valor igual a um, como no trabalho de Silva [13]. 
O método de contato utilizado no modelo é o método de penalidade, por ser o que melhor representa o contato mecânico de um processo que envolve interações térmicas e o uso do recurso de malha adaptativa [4].

A fim de simular os movimentos das ferramentas e do tarugo, algumas restrições de deslocamento foram impostas. Tanto as ferramentas como o tarugo, inicialmente, tiveram todas as possibilidades de deslocamento restringidas a fim de que não apresentassem nenhum deslocamento indesejável antes do início do processo, porém, estas restrições foram alteradas quando uma das ferramentas passou a se movimentar.

Apenas a ferramenta inferior do processo LTC apresentou deslocamento. Portanto, no início do processo o deslocamento da ferramenta inferior na direção horizontal $\mathrm{x}$ foi permitido, com velocidade constante de $0,15 \mathrm{~m} / \mathrm{s}$.

$\mathrm{O}$ tarugo apresenta modificações nas restrições às quais estava submetido ao início do movimento da ferramenta inferior, sendo que apenas a restrição de deslocamento na direção fora de plano $\mathrm{z}$ foi mantida.

Também se fez uso da atribuição da temperatura para as ferramentas e ao tarugo, sendo que a temperatura imposta às ferramentas foi a mesma da temperatura ambiente de $27^{\circ} \mathrm{C}$ e a temperatura imposta ao tarugo, devido a simulação representar um processo a quente, foi de $1100^{\circ} \mathrm{C}$.

A última etapa da modelagem foi determinar a malha do tarugo. Como foram criados diversos modelos com características diferentes entre eles, a determinação da malha também foi feita de diferentes formas, porém sempre seguindo alguns parâmetros em comum como a malha de elementos quadráticos para todos os modelos e com uma dimensão máxima para cada elemento da malha.

Os primeiros modelos idealizados (Figura 3) foram classificados como "Modelos I" e tinham como objetivo a escolha de valores máximos para as dimensões dos elementos da malha (Tabela 2). Assim, para estes primeiros modelos, a malha foi formulada determinandose um tamanho global aproximado entre os seus elementos a fim de verificar uma densidade com melhor relação de tempo de processamento por precisão. O recurso de malha adaptativa foi utilizado para esses modelos, nos quais a malha foi definida para se reorganizar três vezes a cada dez incrementos de cálculos, a fim de manter um bom aspecto durante a simulação.

Tabela 2: Representação da densidade da malha dos tarugos dos "Modelos I".

\begin{tabular}{ccc}
\hline Nomenclatura & Nós da malha & $\begin{array}{c}\text { Elementos da } \\
\text { malha }\end{array}$ \\
\hline LTC2D 1 & 73 & 60 \\
LTC2D 2 & 91 & 76 \\
LTC2D 3 & 113 & 96 \\
LTC2D 4 & 135 & 116 \\
LTC2D 5 & 247 & 220 \\
LTC2D 6 & 375 & 344 \\
LTC2D 7 & 551 & 512 \\
\hline
\end{tabular}




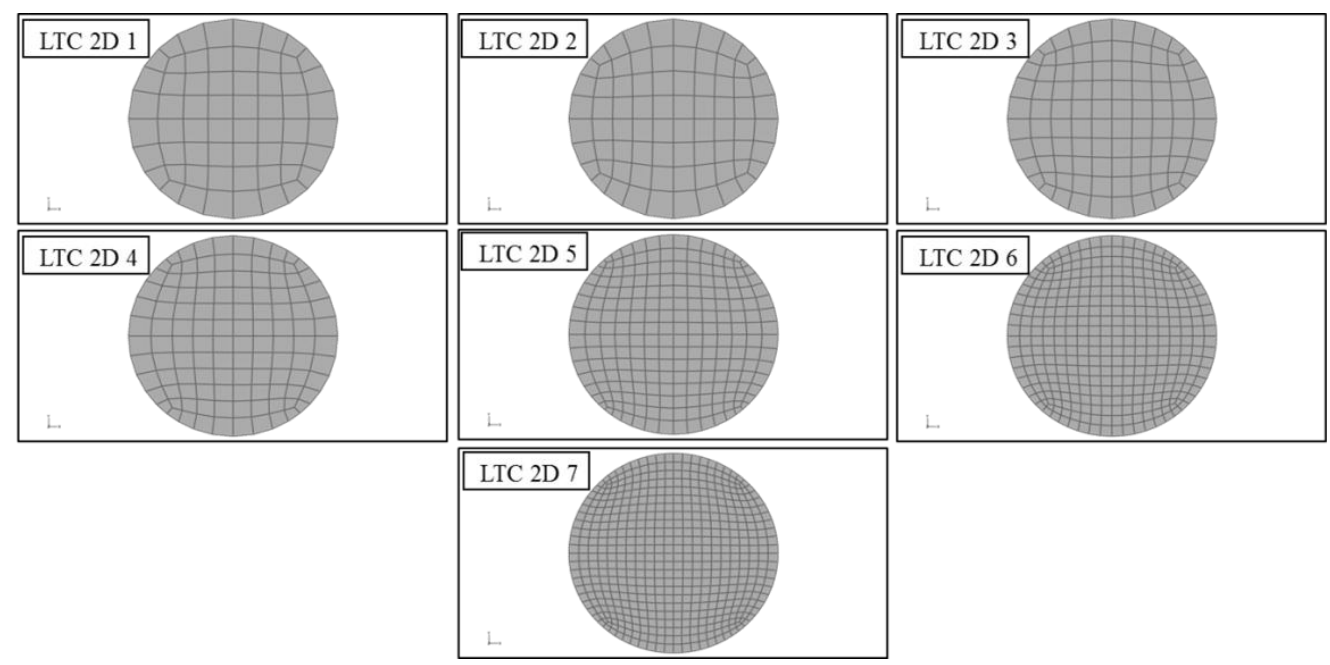

Figura 3: Primeiros modelos formulados a fim de determinar a densidade da malha com melhor relação de tempo de simulação e precisão dos resultados.

Outros modelos formulados, classificados como "Modelos II" e que são demonstrados na Figura 4, tiveram por objetivo validar os modelos do processo numérico através de comparação com resultados encontrados na literatura para o formato de um vazio no interior do tarugo após ser submetido, primeiramente, ao processo LTC com duas ferramentas planas e, posteriormente, com três ferramentas cilíndricas.

Para a formulação desses modelos, o vazio modelado no centro de cada tarugo apresentou diâmetro de $0,6 \mathrm{~mm}$, ou seja, $1 / 40$ do diâmetro do tarugo, o modelo de ferramenta plana apresentou velocidade de $0,15 \mathrm{~m} / \mathrm{s}$ em ambas as ferramentas para acentuar a forma final do vazio e as ferramentas cilíndricas foram modeladas com diâmetro de $120 \mathrm{~mm}$ e velocidade angular de $0,6 \mathrm{~m} / \mathrm{s}$. Todos os demais parâmetros de modelagem foram mantidos como descritos no modelo anterior, sendo acrescentado um fator de atrito constante de 0,5 na lateral do vazio para o caso de se tocar devido a deformação. Por último, foi gerado também um refino de malha na região central do tarugo a fim de evitar erros de distorção da malha.

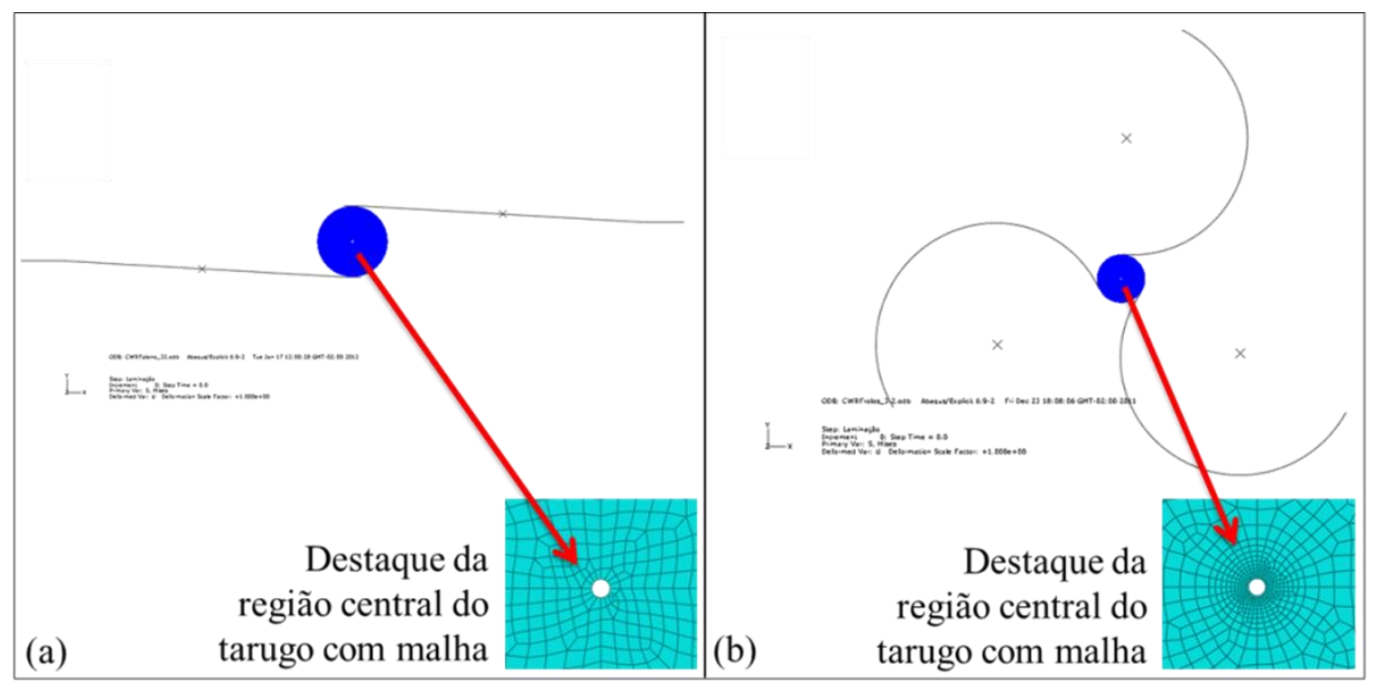

Figura 4: Modelos para a validação do processo numérico com a região central em destaque:

(a) modelo de ferramentas planas e (b) modelo com três rolos cilíndricos. 
Os próximos modelos formulados, denominados "Modelos III", foram elaborados a fim de estudar a influência de vazios na região central do tarugo, mantendo inalterados os parâmetros dos "Modelos I", porém apresentando diferenças pelo uso de uma malha com refino no centro do tarugo como mostrado na Figura 5, pela presença de vazios e pelo acréscimo do fator de atrito constante de 0,5 nas laterais dos vazios para o caso de se tocarem devido à deformação.

Os vazios foram definidos como sendo circulares por esta geometria ser a mais utilizada para a representação de defeitos de porosidade dos aços e, principalmente, quando se faz uso de recursos MEF como observado nos trabalhos de Chen [3] e Tvergaard et al. [15].

Os "Modelos III" apresentaram tarugos com um, quatro e cinco vazios distribuídos na sua região central com diâmetro igual a $0,6 \mathrm{~mm}$ (1/40 do diâmetro), sendo este valor definido maiores do que o real a fim de acelerar o tempo de simulação.

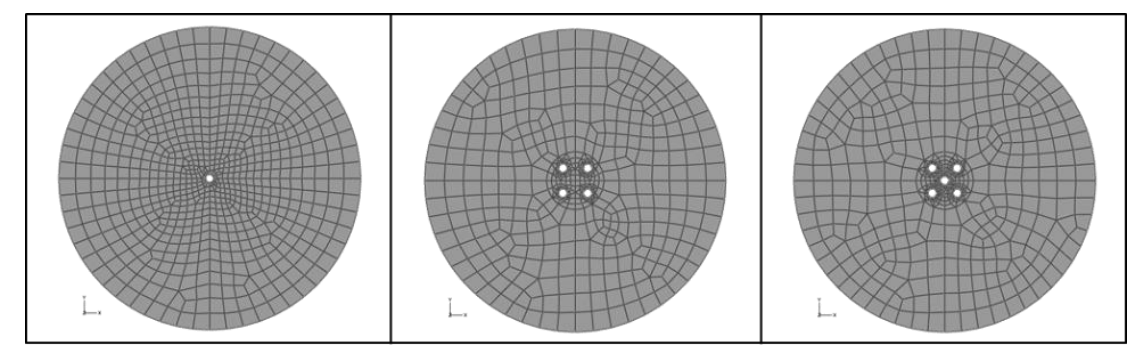

Figura 5: Tarugos modelados com vazios internos de diâmetro igual a 0,6mm com destaque para a densidade da malha.

Segundo Dixin et al. [5], além dos vazios, o desempenho e a qualidade dos aços também são influenciados pela quantidade, tipo, forma, tamanho, distribuição e comportamento das inclusões sob deformação. Por isso, modelos que apresentaram inclusões nos locais dos vazios foram realizados e nomeados como "Modelos IV". Estes modelos apresentaram diferenças quanto aos parâmetros de modelagem numérica ao serem comparados com os "Modelos III" por ter sido acrescentado um fator de atrito constante igual a 0,5 entre o material matriz do tarugo e as inclusões.

Outro fator importante destes modelos são as propriedades dos materiais adotados nas inclusões, que foram baseados no material do tarugo (aço microligado 38MnSiVS5), sendo que houve alteração apenas nos valores das tensões da curva tensão deformação, que receberam valores hipotéticos como no trabalho de Ervasti et al. [7], no qual as inclusões consideradas duras apresentaram valores de tensão três vezes mais altas e as inclusões consideradas macias apresentaram valores de tensão três vezes mais baixas.

Outro aspecto destes "Modelos IV" está relacionado com a geometria das inclusões, que foram idealizadas segundo o trabalho de $\mathrm{Yu}$ et al. [17], de modo que as inclusões apresentaram as formas geométricas de um circulo (diâmetros de 0,6mm), de um quadrado e de um triângulo, como apresentado na Figura 6. Devido às geometrias das inclusões serem diferentes, suas áreas mantiveram o mesmo valor a fim de que as diferenças de tamanho não afetassem o campo de tensão [5], permitindo que fosse possível verificar a interferência do formato das inclusões sem resultados associados diretamente às suas dimensões. 


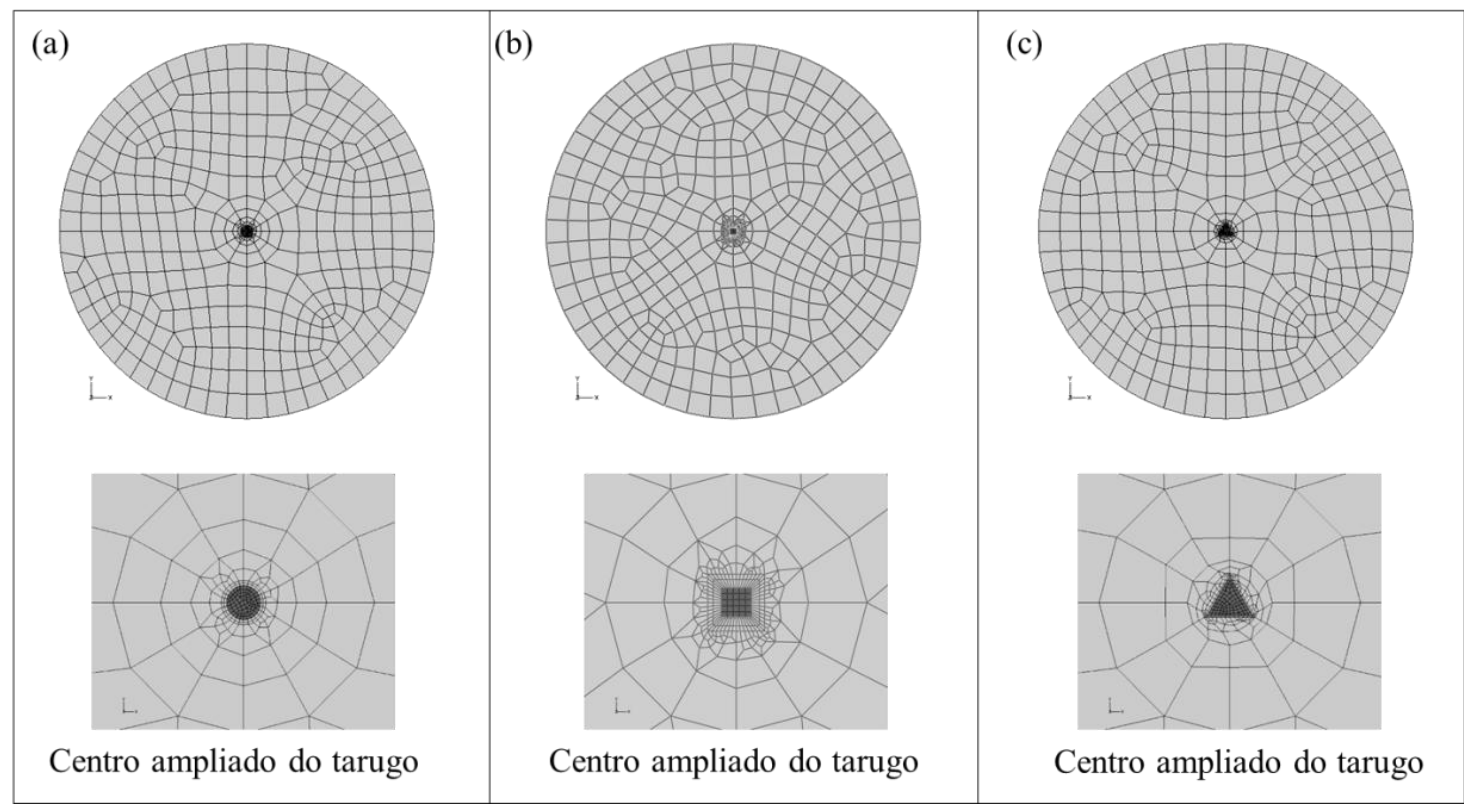

Figura 6: Tarugos modelados com inclusões internas: (a) inclusão circular central, (b) inclusão quadratica central e (c) inclusão triangular central.

Um último modelo idealizado, o "Modelo V", utiliza um recurso peculiar do software Abaqus, o recurso de análise de nucleação e coalescência de poros, a fim de confirmar a ocorrência de vazios na região central do tarugo, como descrito na literatura, e de verificar a eficácia deste recurso.

Este "Modelo V" foi concretizado numericamente seguindo os parâmetros adotados nos "Modelos I", porém com uma ressalva, que foi a adição de propriedades de porosidade na caracterização numérica do aço microligado 38MnSiVS5:

- Parâmetros do material: $q_{1}=1,5 ; q_{2}=1,0$ e $q_{3}=2,25$;

- Fração de volume dos vazios nucleados $f_{N}=0,04$;

- Desvio padrão $s_{N}=0,1$;

- Valor médio da distribuição normal da tensão de nucleação $\varepsilon_{N}=0,3$;

- Valor crítico da fração de volume de vazios $f_{c}=0,15$;

- Valor da fração de volume de vazios para a falha $f_{F}=0,25$ e

- Densidade relativa $r=0,990203$ (obtida por análise de micrografia).

Como os dados para materiais porosos são específicos para cada aço devendo ser obtidos por métodos experimentais específicos, com exceção do valor da densidade relativa que foi obtida através de análise micrográfica, os valores apresentados neste estudo, segundo Sánchez et al. [12], são valores comuns tipicamente adotados para os aços.

\section{RESULTADOS}

Os primeiros modelos ("Modelos I") foram elaborados com o objetivo de determinar um parâmetro máximo para as dimensões dos elementos da malha, por comparação de resultados. 
Sete modelos que se diferenciam apenas quanto à densidade de malha foram simulados e foi utilizado dois pontos, destacados na Figura 7, para comparação dos resultados, como apresentado nas Figuras 8 e 9.

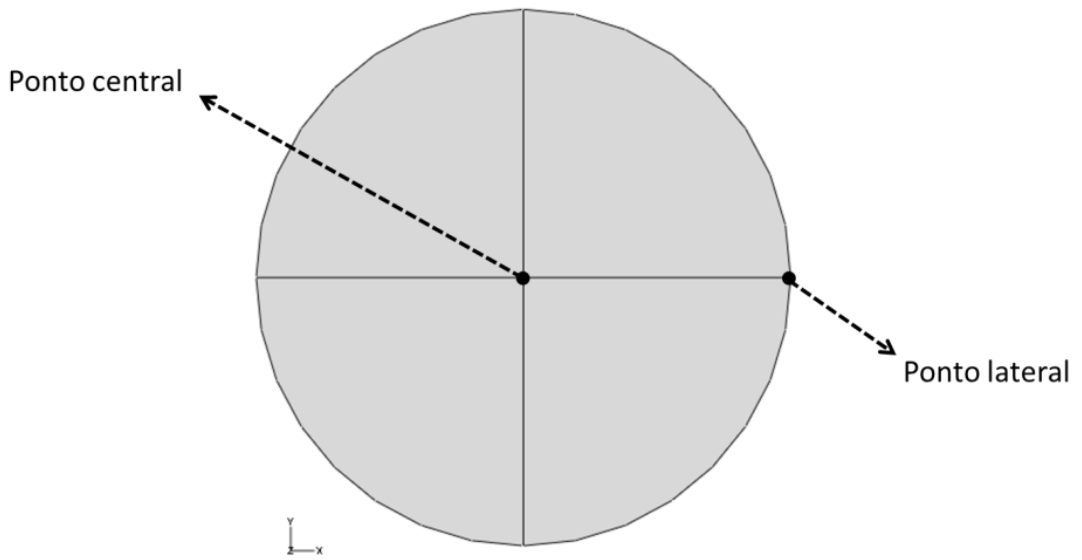

Figura 7: Representação dos pontos utilizados para análise de resultados.

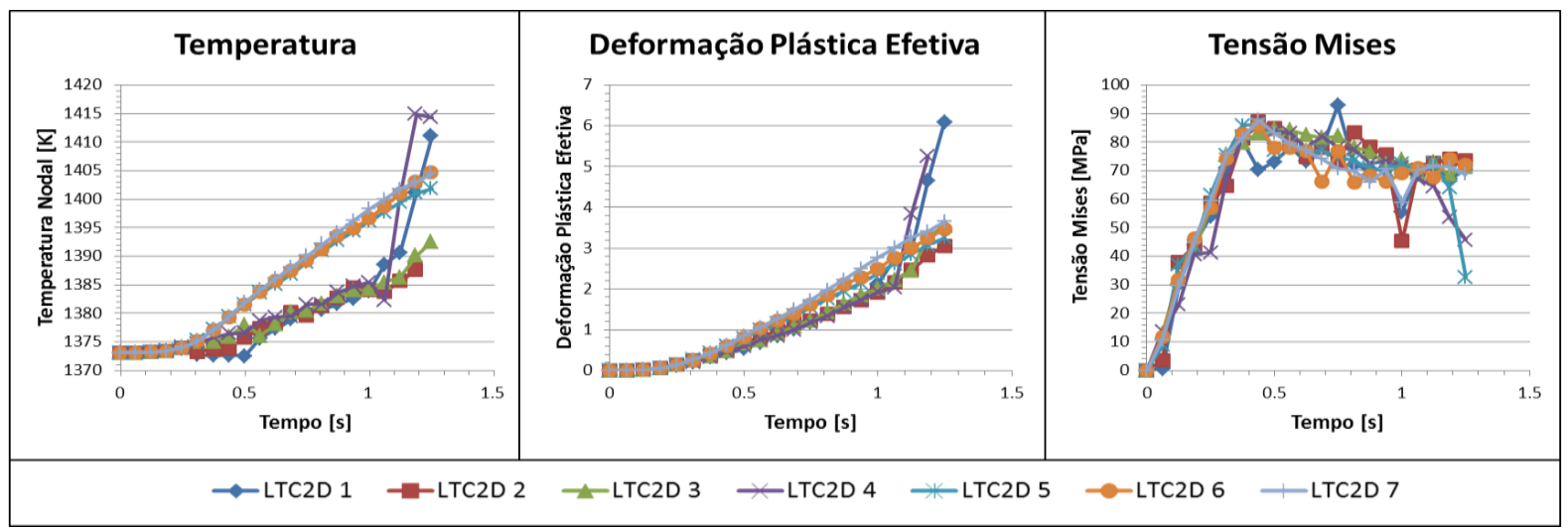

Figura 8: Comparação dos resultados dos "Modelos I" no ponto central.

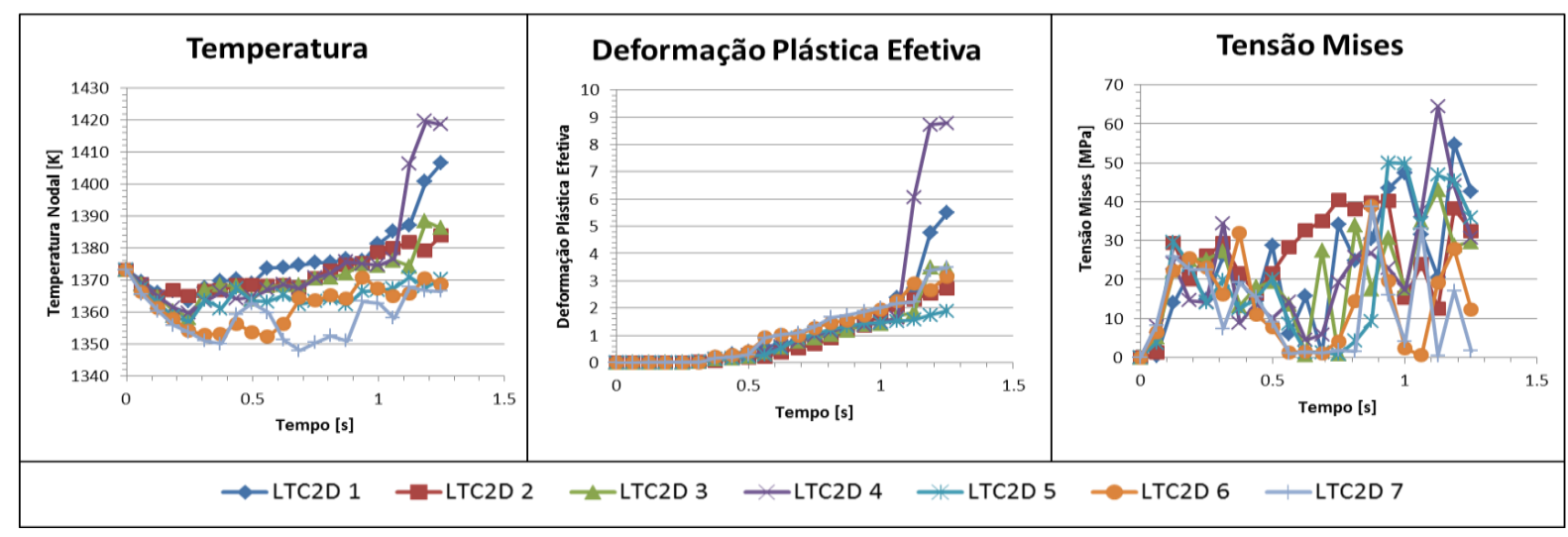

Figura 9: Comparação dos resultados dos "Modelos I" no ponto lateral.

Ao comparar os gráficos, observou-se que os resultados do modelo "LTC2D 6" convergiram aos do modelo "LTC2D 7" que teve o maior refino de malha, porém que teve maior tempo em simulação, assim, o modelo "LTC2D 6" foi escolhido como sendo a base 
para todas as modelagens. Por tanto, nenhum outro modelo criado apresentou as dimensões dos elementos da malha maior que o utilizado nesse modelo "LTC2D 6".

Os "Modelos II" foram realizados a fim de validar, com base em resultados da bibliografia, a modelagem numérica no software Abaqus do processo LTC. Como Gentile [8] expressa em seu estudo, defeitos internos apresentam diferentes formatos por serem oriundos de processos com ferramentas planas quando comparados com processos nos quais se faz uso de três rolos. Desta forma, dois modelos foram formulados, um com duas ferramentas planas e outro com três rolos. Ambos os modelos apresentavam o tarugo com um vazio central.

Os resultados numéricos para a predição da forma final dos vazios, tanto para as ferramentas planas quanto para as ferramentas de três rolos, apresentaram boa concordância com o aspecto final esperado para o vazio informado na literatura (Figura 10).

Ferramentas Planas

Três Rolos

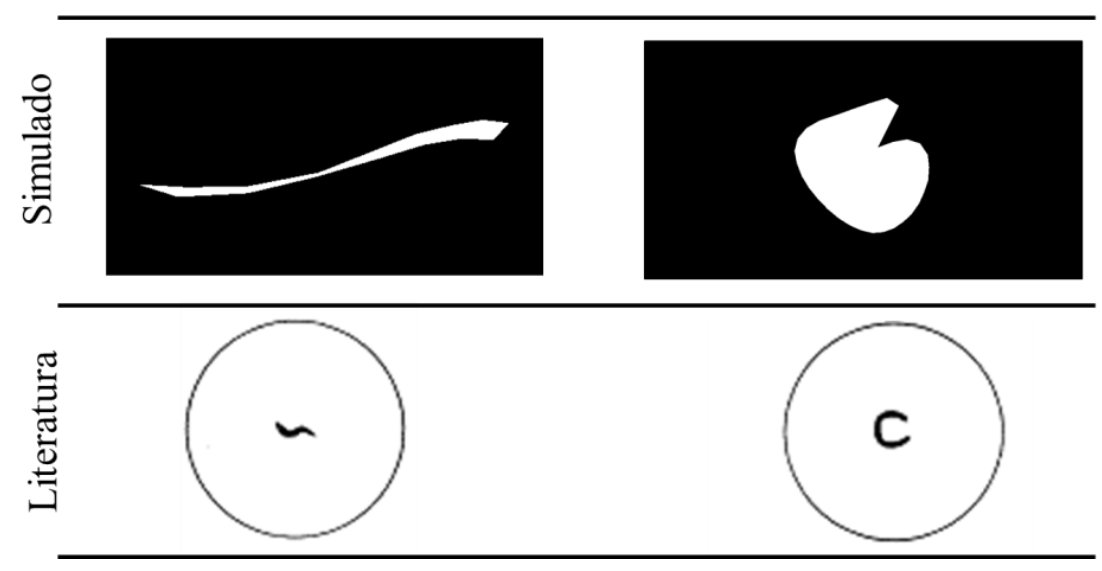

Figura 10: Comparação de resultados numéricos com resultados bibliográficos de vazios internos no centro do tarugo para diferentes configurações de ferramentas de LTC.

Após validar a modelagem numérica do processo, os resultados do modelo "LTC2D 6" (representados na Figura 11) foram analisados e tiveram os resultados de dois pontos (como demonstrado pela Figura 7) dispostos em gráficos pelas Figuras 12 e 13.
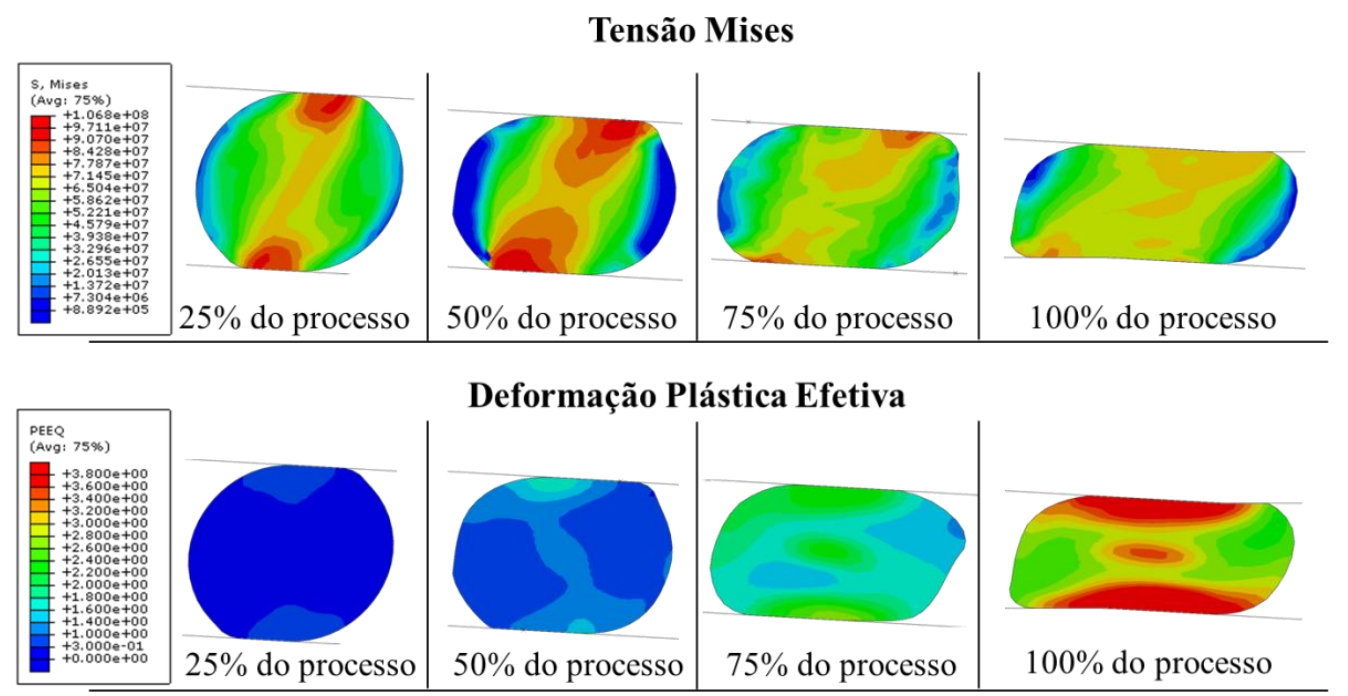

Figura 11: Etapas dos resultados de tensão Mises e da deformação plástica efetiva oriundos do modelo "LTC2D 6". 


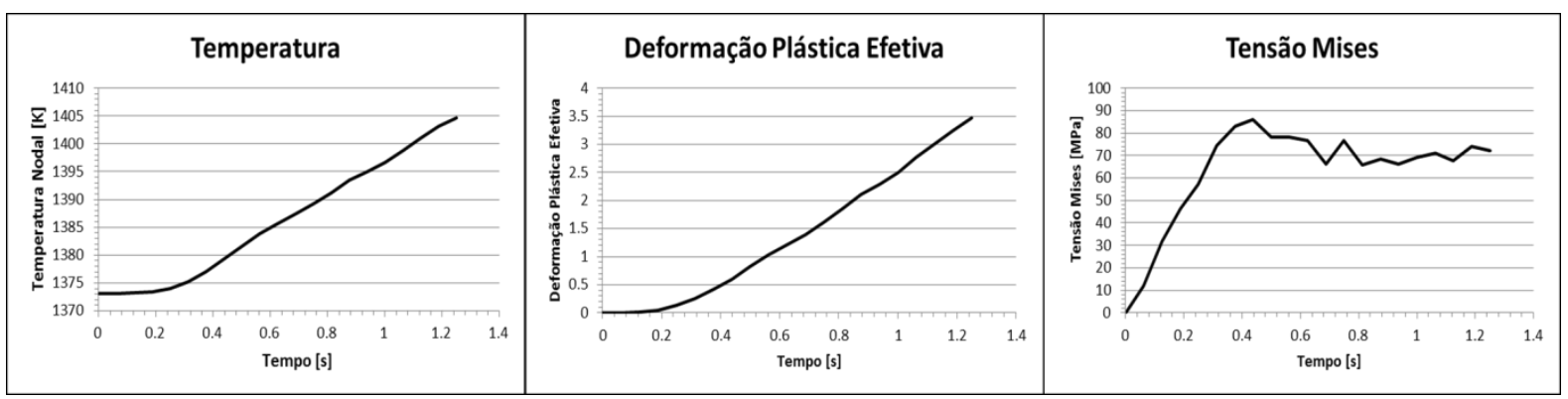

Figura 12: Resultados do ponto central do modelo "LTC2D 6".

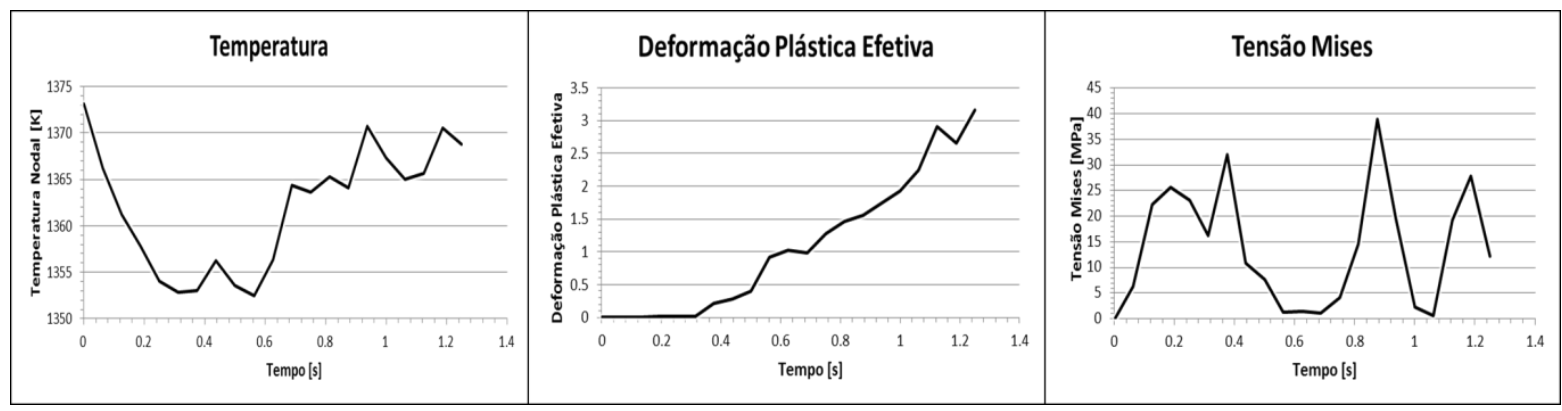

Figura 13: Resultados do ponto lateral do modelo "LTC2D 6".

Neste modelo, analisando a Figura 11 e os gráficos das Figuras 12 e 13, fica visível que o campo de deformação plástica efetiva apresentou maiores valores na região central do tarugo.

A tensão também apresentou os maiores valores e a tendência de se manter constante na região central do tarugo, mas apresentou altos valores também na forma de uma linha que corta o tarugo entre a área de contato com a ferramenta superior até a inferior. Saindo do centro para a região mais externa do tarugo, a tensão apresentou picos que indicam o momento em que passam próximos ao contato com as ferramentas, sendo este momento o mais crítico para a porção superficial do tarugo.

Já a temperatura na região central do tarugo tendeu a aumentar durante o início do processo, como demonstrado no gráfico da Figura 12, devido aos maiores níveis de deformação presentes, o que resultou em geração de energia na forma de calor. Porém, próximo à região externa do tarugo, o valor da temperatura apresentou variações, pois ocorreu a geração de calor devido ao atrito, mas também ocorreu transferência de calor pelo contato com as ferramentas e por radiação com o meio ambiente.

A presença dos maiores valores de deformação, tensão e temperatura na região central do tarugo indicou que esta região apresentou a maior complexidade do processo de deformação, com elevados níveis de solicitação, sendo assim a região mais suscetível a nucleação e desenvolvimentos de defeitos internos como foi descrito por Li et al. [10].

O gráfico da Figura 14, que representa a curva tensão versus deformação no ponto central do tarugo do modelo "LTC2D 6", demonstrou que a sua microestrutura está sofrendo alterações. Inicialmente, a tensão de escoamento aumentou devido ao encruamento do aço até atingir uma deformação crítica representada pelo pico de tensão, que indicou a ocorrência da recristalização dinâmica e, por fím, um estado de equilíbrio entre o encruamento e o amaciamento térmico foi atingido. Foi possível verificar este efeito também nas imagens do 
processo de tensão da Figura 11, pois, aproximadamente, após metade do processo o valor da tensão no tarugo parou de aumentar e começou a diminuir até um ponto em que passou a permanecer constante.

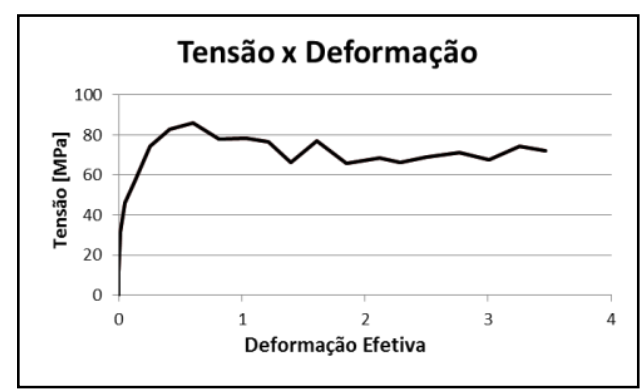

Figura 14: Curva Tensão versus Deformação do ponto central do modelo "LTC2D 6".

Diferentes modelos com vazios internos foram simulados a fim de verificar como estes vazios e o tarugo se comportam durante o processo LTC.

A Figura 15 representa os resultados obtidos para o modelo com um vazio interno de diâmetro igual a $0,6 \mathrm{~m}$.

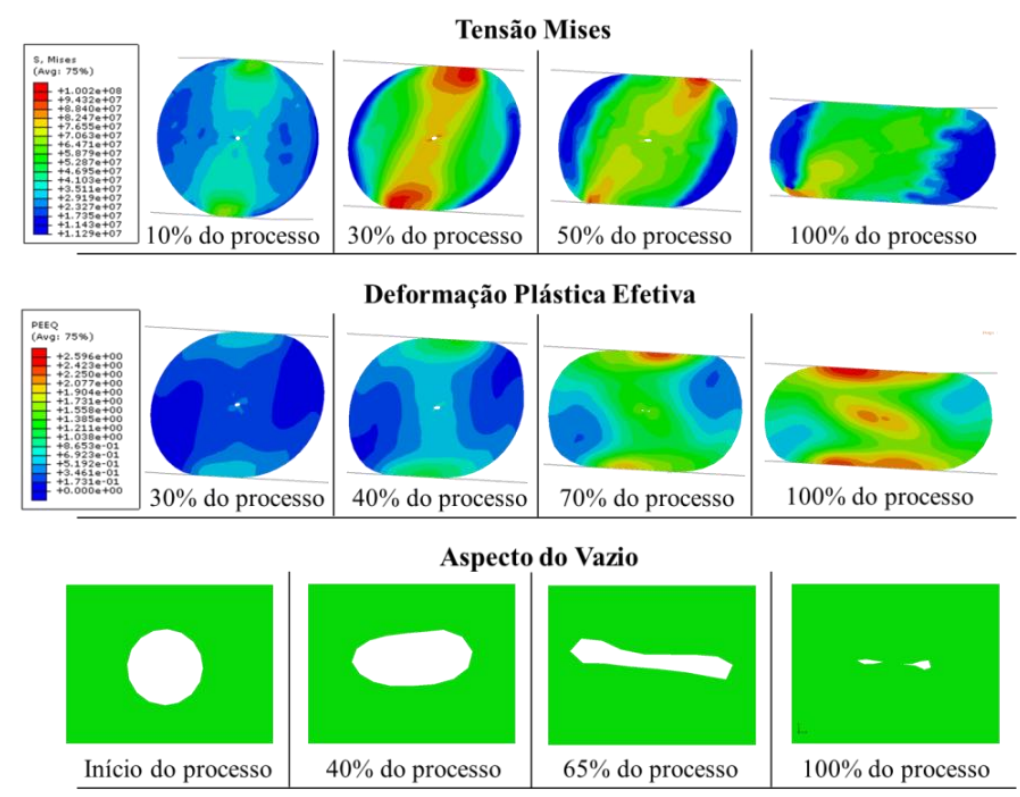

Figura 15: Etapas dos resultados da simulação do modelo com um vazio no centro do tarugo.

Este modelo com um vazio apresentou resultados muito próximos aos do modelo denso, sendo que apenas a deformação plástica efetiva resultou em valores pouco menores em relação ao modelo denso.

Devido ao grande tempo de simulação gasto com o modelo com um vazio interno, e sabendo que os próximos modelos seriam mais complexos e apresentariam quantidades maiores de interações, passou-se a utilizar o recurso de escala de massa.

A fim de determinar um valor aceitável para utilizar o método de escala de massa, outros seis modelos, do modelo com um vazio interno, foram criados, com cada um 
apresentando um valor diferente de escala de massa, sendo estes valores de: 10, 20, 35, 50, 75 e 100 .

Os resultados obtidos destes modelos com o recurso de escala de massa foram comparados entre si e com o modelo original sem este recurso. Alguns resultados destas comparações estão apresentados nas Figuras 16, 17 e 18.

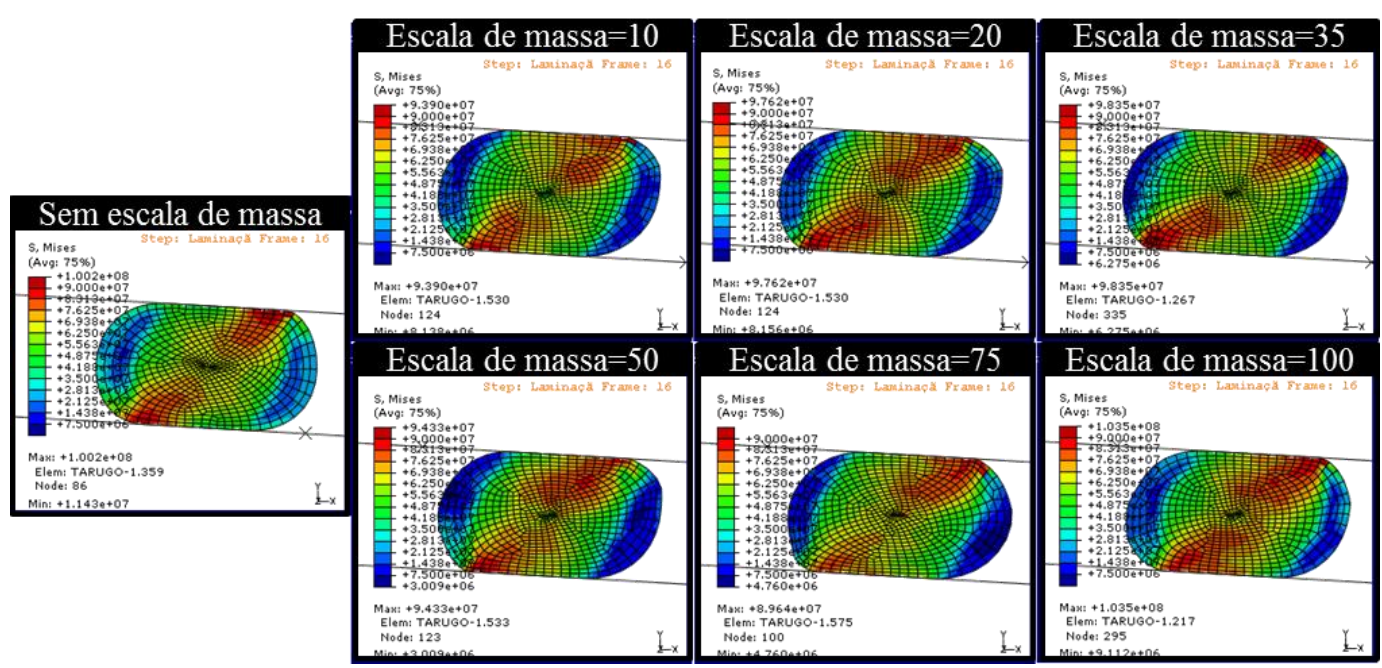

Figura 16: Representação do campo de tensão dos modelos com o uso do recurso de escala de massa em comparação com o modelo sem o recurso a $80 \%$ do processo.

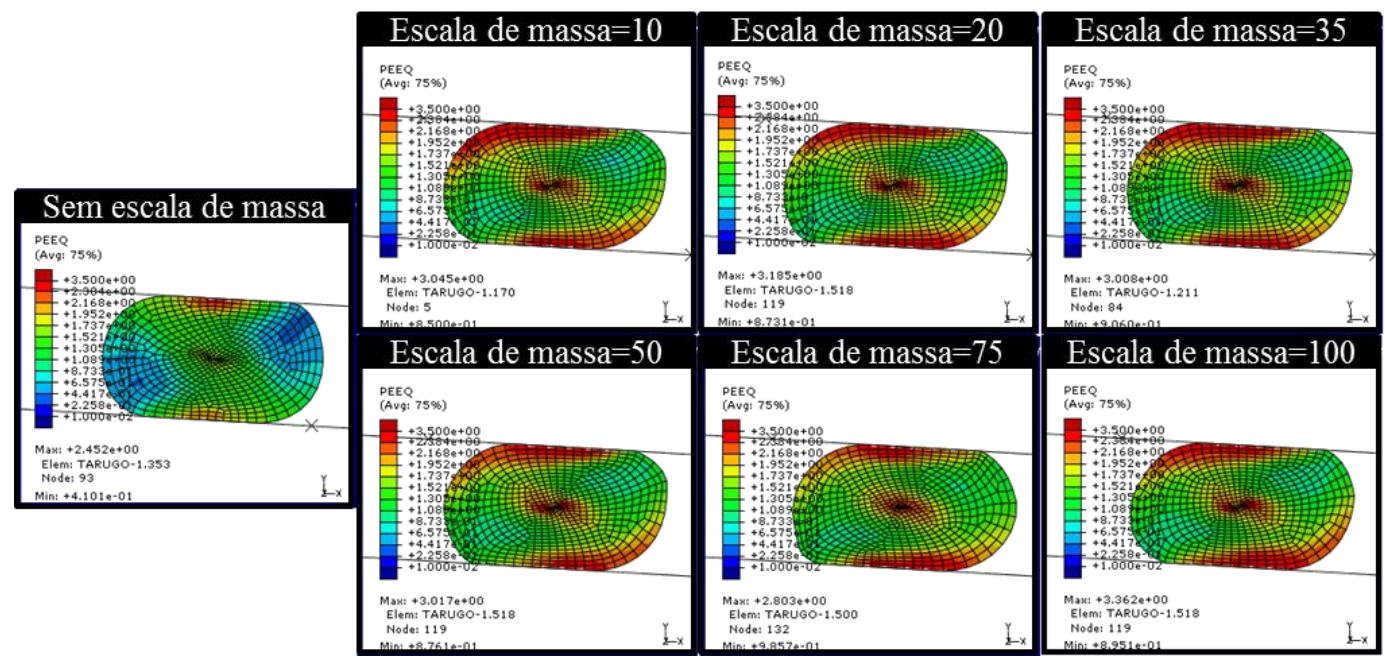

Figura 17: Representação da deformação plástica efetiva dos modelos com o uso do recurso de escala de massa em comparação com o modelo sem o recurso a $80 \%$ do processo. 


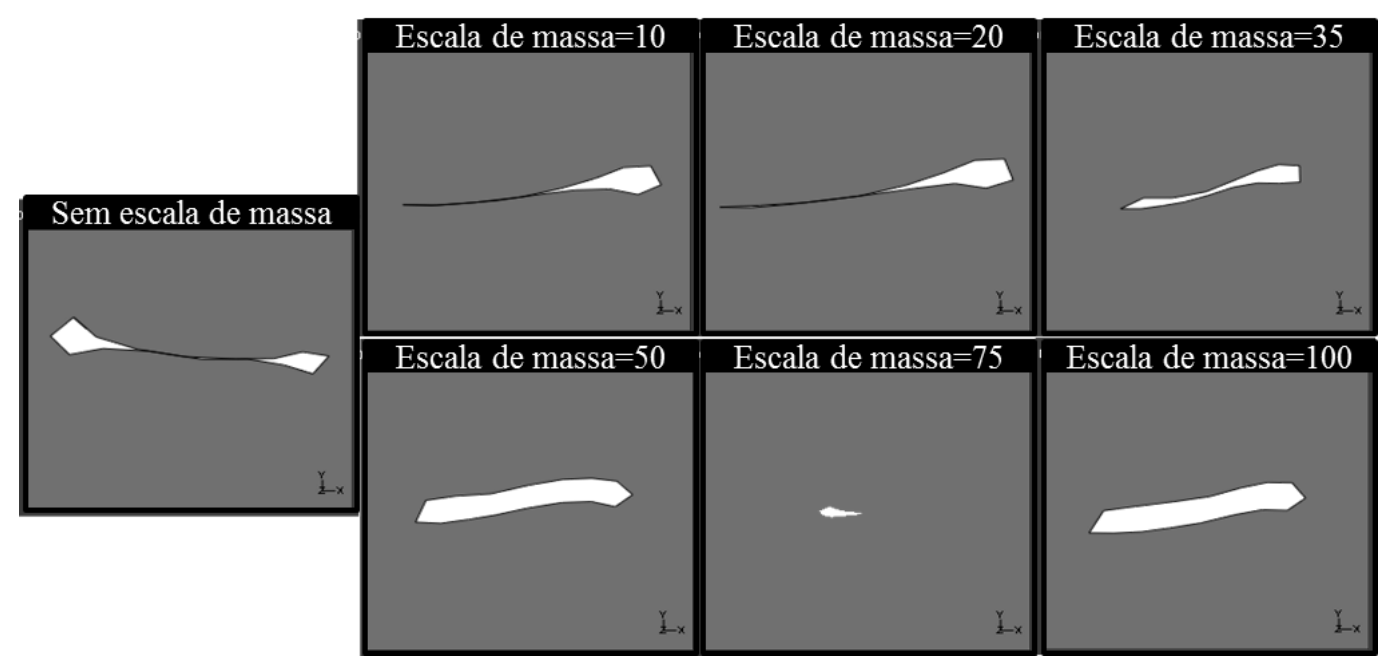

Figura 18: Representação do aspecto do vazio dos modelos com o uso do recurso de escala de massa em comparação com o modelo sem o recurso a $80 \%$ do processo.

De forma geral, os modelos com o uso do recurso de escala de massa apresentaram resultados pouco diferentes aos do modelo sem o recurso, sendo que os modelos com escala de massa superior a 35 apresentaram os resultados que mais desviaram dos resultados esperados.

Por comparação dos resultados em dois pontos, um situado logo acima do vazio e o outro situado na extremidade direita do tarugo, determinou-se que o valor de escala de massa igual a 35 apresentou o menor tempo de simulação com resultados confiáveis, sendo que apenas os valores da deformação plástica efetiva apresentaram desvio considerável em relação ao modelo sem escala de massa, como demonstrado nos gráficos da Figura 19. Porém como esta variável é mais utilizada para a predição da falha interna por análise do local onde apresenta maior concentração e intensidade [10], e como a falha interna (na forma de vazios) já esta presente nestes modelos, o seu valor em si não é relevante.

Assim, como as variáveis obtidas no modelo com escala de massa igual a 35 apresentaram resultados aceitáveis e como o modelo original sem escala de massa gastou aproximadamente 55 horas para ser simulado, enquanto que o modelo com escala de massa igual a 35 gastou cerca de 5 horas, uma redução apreciável no tempo de simulação, os outros modelos criados apresentaram o uso do recurso de escala de massa com valor igual a 35. 


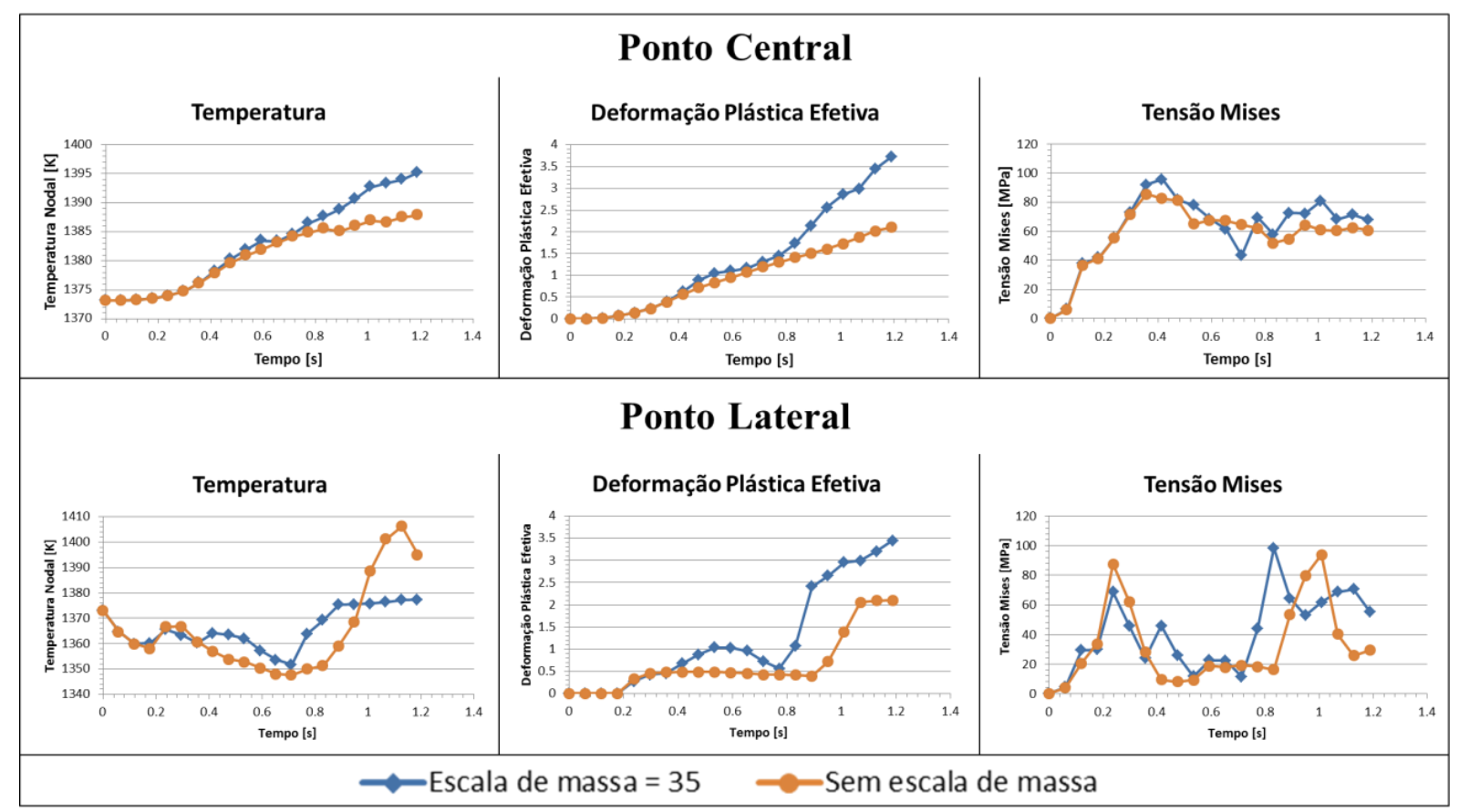

Figura 19: Comparação de resultados entre o modelo original sem escala de massa e o modelo com escala de massa igual a 35 em dois pontos específicos.

Posteriormente, modelos com quatro e cinco vazios na região central do tarugo foram simulados, com os resultados representados na Figura 20.

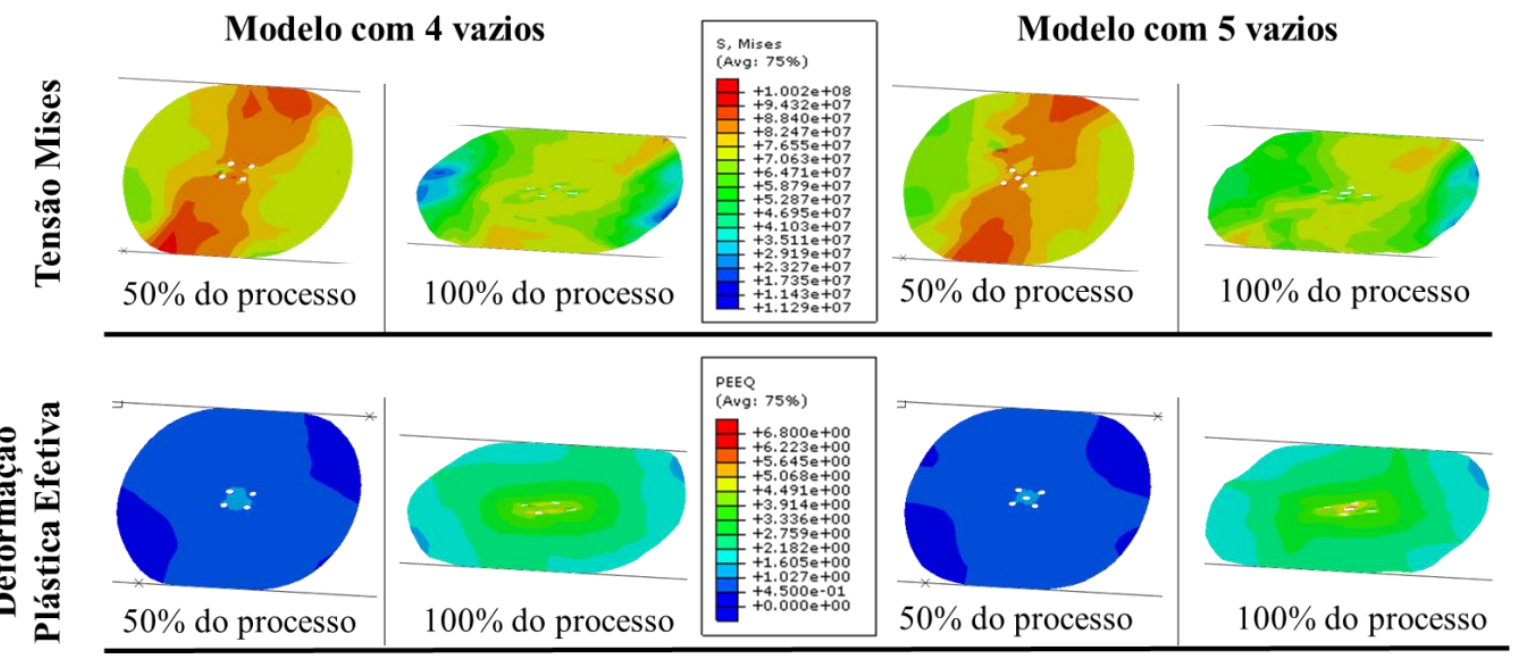

Figura 20: Aspecto dos campos de tensão e de deformação plástica efetiva dos modelos com quatro e cinco vazios.

De modo geral, estes modelos com quatro e cinco vazios apresentaram resultados próximos ao do modelo com um vazio. Assim como no modelo com um vazio, nestes dois modelos, os vazios tenderam a fechar durante o processo e os maiores níveis de tensão e deformação plástica efetiva também mantiveram presentes na região central do tarugo.

O valor da deformação plástica efetiva apresentou consideravelmente maior do que no modelo com um vazio e no modelo sólido, e esse aumento não é explicado pelo recurso de 
escala de massa por apresentar valores bem maiores do que o do modelo base com um vazio central, assim a causa deste aumento é devido a quantidade de vazios no centro do tarugo.

Destacou-se, ainda, que nestes dois novos modelos, as regiões próximas a cada vazio interagiram entre si, porém os valores da tensão não apresentaram diferenças expressivas quando comparado com o de outros modelos.

Já a temperatura é uma variável que praticamente não apresentou alteração entre os modelos, tanto no sólido como no modelo com um, quatro e cinco vazios, desta forma, a variação de temperatura no tarugo não é influenciada pela quantidade de vazios.

Por último, modelos que apresentaram três diferentes formas de inclusões (circulares, quadráticas e triangulares) foram simulados, sendo realizado duas simulações para cada forma de inclusão, uma com inclusões mais macias e outra com inclusões mais duras que o material matriz do tarugo.

Foram utilizados três pontos para a obtenção dos resultados no tarugo, um ponto situado na parte superior das inclusões e chamado de "Ponto central", outro ponto situado na extremidade lateral direita do tarugo, nomeado de "Ponto lateral" e o último ponto, o "Ponto intermediário" localizado entre o "Ponto central" e a extremidade superior do tarugo. Os resultados dos modelos foram comparados e dispostos em gráficos (Figura 21), a fim de determinar o que os diferentes tipos de inclusões influenciam no material ao seu redor.

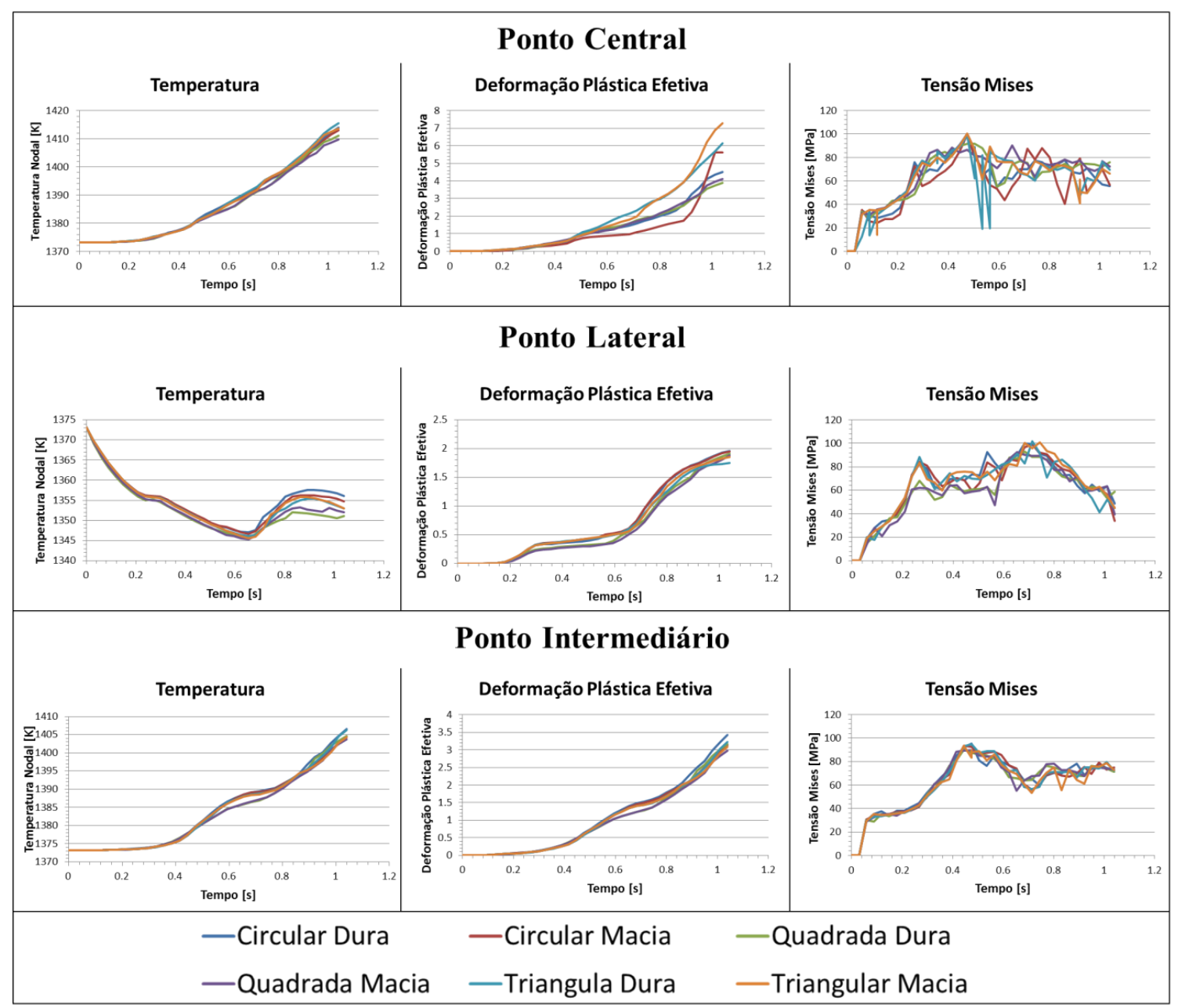

Figura 21: Comparação em diferentes pontos dos resultados dos modelos com inclusões. 
Como está representado pela comparação dos resultados da Figura 21, as diferentes formas e propriedades das inclusões não geraram interferências apreciáveis nos resultados.

Tanto os valores da temperatura quanto da tensão não apresentaram diferenças consideráveis em comparação com os modelos sólido e com vazios. Os valores da deformação plástica efetiva na região central do tarugo próximo as inclusões, apresentou valores próximos aos dos modelos com quatro e cinco vazios, assim, apresentando diferença apenas quando comparado com os modelos com um vazio ou sólido.

$\mathrm{O}$ aspecto das inclusões e dos tarugos ao serem deformados merecem destaque e estão representado na Figura 22.

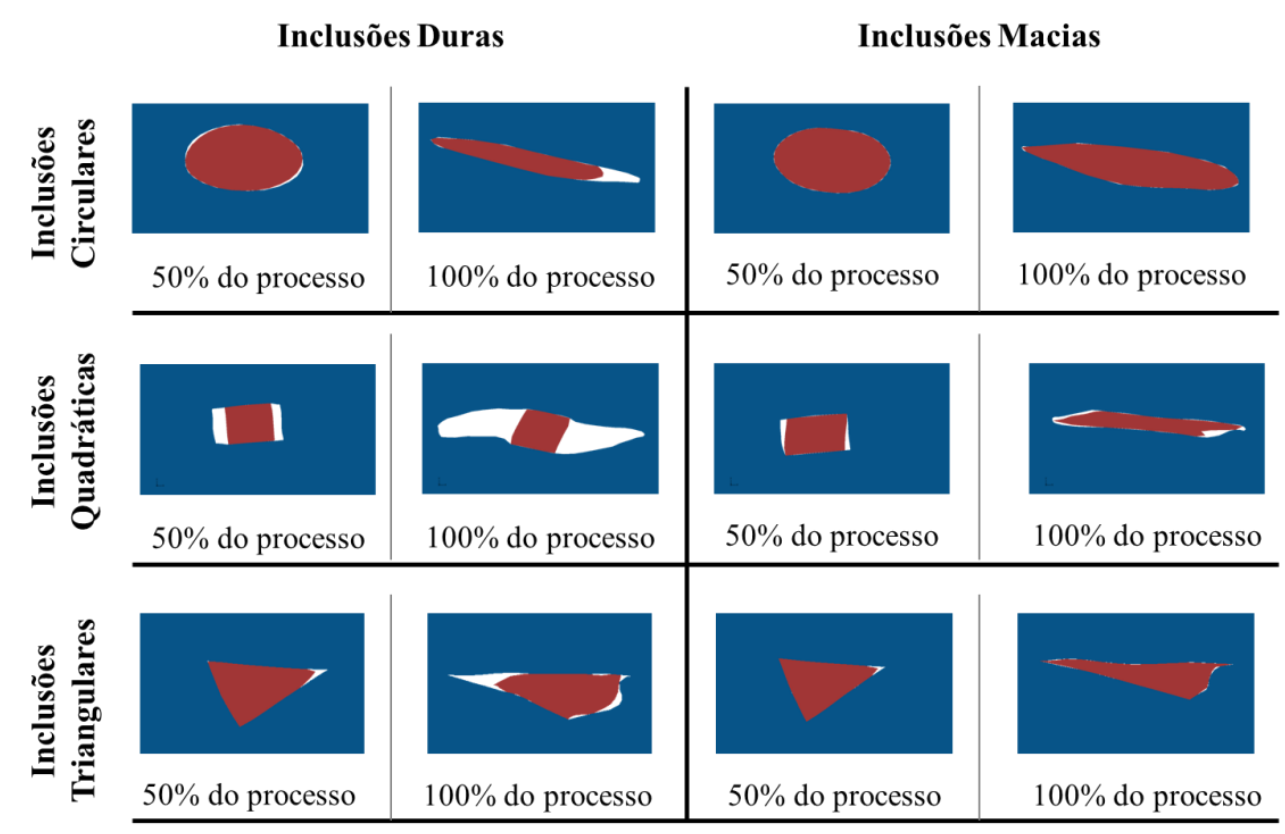

Figura 22: Aspecto do centro do tarugo dos modelos com inclusões.

Os modelos com inclusões circulares e triangulares apresentaram a formação de vazios menores ao redor das inclusões devido às mesmas acompanharem a deformação do tarugo, enquanto que os modelos com inclusões quadráticas apresentaram os maiores vazios formados. Em todos os modelos - principalmente nos modelos de inclusões quadráticas - os vazios formados tenderam a uma forma alongada com as extremidades afinadas, sendo que para as inclusões duras, a forma alongada dos vazios apresentaram o maior afinamento.

$\mathrm{O}$ último modelo analisado, o "Modelo V" com propriedades de porosidade, foi analisado e verificado que, inicialmente, o tarugo praticamente não apresentou sinais de porosidade, mas depois de certo tempo, aumentou e passou a se concentrar na região central como observado no gráfico "Fração de volume de vazios total" da Figura 23. Após cerca da metade do tempo de simulação, apesar da maior concentração de porosidade ainda ser no centro do tarugo, a sua intensidade reduz, o que pode ser explicado pela ocorrência do fechamento dos vazios devido a grande deformação imposta ao modelo bidimensional (faz-se importante salientar que em um processo real existe a deformação axial do tarugo, assim, é provável que a densidade da porosidade não diminua tanto como obtido nesse modelo bidimensional). 
O Abaqus analisa dois diferentes métodos para a predição da densidade de porosidade no modelo. Um é através da análise da formação de vazios pela nucleação e o outro é pela coalescência dos vazios.

A fração de volume de vazios por nucleação apresentou aspecto de desenvolvimento praticamente igual por todo o tarugo, sem apresentar sinal de desenvolvimento no início do processo, mas ao desenrolar do tempo passou a ganhar intensidade, principalmente na região central, até atingir um valor em que esse ganho foi cessado e permaneceu constante.

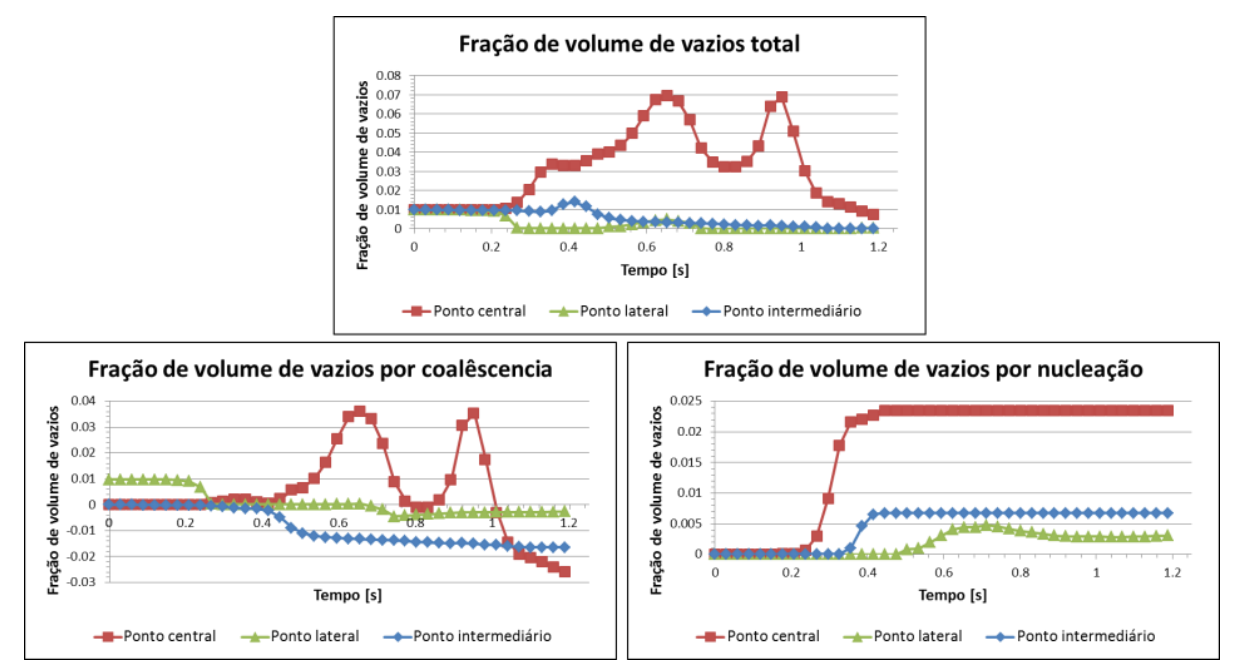

Figura 23: Aspecto do centro do tarugo dos modelos com inclusões.

A fração de volume de vazios por coalescência apresentou um aspecto interessante, no início do processo tendeu a permanecer sem valor, quando passa então a aumentar no centro do tarugo, porém, após cerca de metade do tempo do processo, passa a diminuir até chegar a zero, que é quando a intensidade de nucleação já está constante, e o ciclo se repete voltando a aumentar devido a grande deformação e por ainda existirem vazios sendo nucleados e então diminui pela mesma deformação que continua a aumentar. Nesse último ciclo o valor diminui até valores negativos, indicando a ocorrência da eliminação de vazios, o que pode ser explicado pelo alto nível de deformação plástica que o ocorre no tarugo, forçando o fechamento dos vazios.

Fora da região central do tarugo, a fração de volume de vazios por coalescência ocorre de forma diferente do que no centro, sendo que praticamente não apresenta o efeito de coalescência devido ao baixo número de vazios que nucleiam nessa região, mas apresentam o efeito de fechamento de vazios já que ocorre deformação nessas regiões.

\section{CONCLUSÕES}

O Método de Elementos Finitos do processo LTC apresenta boa concordância com os resultados esperados.

Os maiores níveis de deformação, tensão e temperatura são presentes na região central do tarugo, indicando que esta região apresenta os maiores níveis de solicitação, sendo assim a região mais suscetível a nucleação e desenvolvimentos de defeitos internos. 
Sinais de alteração na microestrutura da região central do tarugo, pela recristalização dinâmica, esta presente nos resultados numéricos.

Vazios na região central do tarugo são relevantes quando há a presença de mais de um vazio e estejam próximos a fim de que ocorra a interação entre seus campos de tensão e deformação, e por apresentarem elevados valores nesta região central.

O campo de tensão, assim como o de deformação e a temperatura não sofrem quase nenhuma alteração devido à forma das inclusões ou a suas propriedades. Sendo que os valores das variáveis se mantiveram muito próximos dos observados quando existem mais de um vazio no material matriz. Porém, o formato da inclusão se destaca quando analisado o seu aspecto final no interior do material matriz, sendo que, para inclusões quadráticas este aspecto se apresenta mais critico por gerar maiores vazios ao seu redor.

\section{REFERÊNCIAS}

[1] ALTENHOF, W.; ZAMANI, N.; NORTH,W.; ARNOLD, B. Dynamic stress concentrations for an axially loaded strut at discontinuities due to an elliptical hole or double circular notches. International Journal of Impact Engineering, v.30, p. 255-274, 2004.

[2] BATTIN, Aditya Ashok. Finite element analysis of forging. 2009. 55p. Master of Science - Faculty of the Graduate School, University of Texas, Arlington.

[3] CHEN, D. Rigid-plastic finite element analysis of plastic deformation of porous metal sheets containing internal void defects. Journal of Materials Processing Technology, v.180, p.193-200, 2006.

[4] Dassault Systèmes Simulia Corp. Special-Purpose Techniques. In: .Abaqus analyses user's manual, version 6.9. Providence: Dassault Systèmes Simulia Corp. 2009, v.2, cap.11, p.11.7.1-1a 11.7.1-13.

[5] DIXIN Y.; JINGPEI, X.; KEFENG, Z.; ZONGFA, L.; AIQIN, W.; WENYAN, W. Numerical simulation of stress field in inclusions of large rudder arm steel castings.China Foundry, v.6, p.219-225, 2009.

[6] DONG, Y.; TAGAVI; K. A.; LOVELL, M. R.; DENG, Z. Analysis of stress in cross wedge rolling with application to failure. International Journal of Mechanical Sciences, v.42, p.1233-1253, 2000.

[7] ERVASTI, E.; STÅHLBERG, Ulf. Void initiation close to a macro-inclusion during single pass reductions in the hot rolling of steel slabs: A numerical study. Journal of Materials Processing Technology, v. 170, p. 142-150, 2005.

[8] GENTILE, Fernando César Gentile. Estudo do processo de laminação transversal com cunha (cross wedge rolling) para fabricação de eixos escalonados. 2004. 190p. Tese (doutorado) - Faculdade de Engenharia Mecânica, Universidade Estadual De Campinas, Campinas. 
[9] LI, Q.; LOVELL, M. R; SLAUGHTER, W.; TAGAVI, K. Investigation of the morphology of internal defects in cross wedge rolling. Journal of Materials Processing Technology, v.125-126, p.248-257, 2002.

[10] LI, Q. Lovell, M. R. The establishment of a failure criterion in cross wedge rolling.The International Journal of Advanced Manufacturing Technology, v.24, n.3-4, p.180189, 2004.

[11] PATER, Z. Theoretical and experimental analysis of cross wedge rolling process. International Journal of Machine Tools and Manufacture, v.40, p.49-63, 2000.

[12] SÁNCHEZ, P.J.; HUESPE; A.E.; OLIVER, J.On some topics for the numerical simulation of ductile fracture. International Journal of Plasticity, v. 24, p.1008-1038, 2008.

[13] SILVA, Mario Luiz Nunes. Otimização do processo de laminação transversal com cunha para a produção de eixos com aço SAE 1045. 2008. 108p. Tese (doutorado) Faculdade de Engenharia Mecânica, Universidade Estadual De Campinas, Campinas.

[14] SILVA, M.L.N.; PIRES, G.H.; BUTTON, S.T. Damage evolution during cross wedge rolling of steel DIN 38MnSiVS5. Procedia Engineering, v.10, p.752-757, 2011.

[15] TVERGAARD, V., HUTCHINSON, J. W. Two mechanisms of ductile fracture: void by void growth versus multiple void interaction. International Journal of Solids and Structures, v. 39, p. 3581-3597, 2002.

[16] WANG, M.; LI, X.; DU, F. Analysis of metal forming in two-roll cross wedge rolling process using finite element method. Journal of Iron and Steel Research, v. 16, p. 3843, 2009.

[17] YU, H.; BI, H.; LIU X.; CHEN L.; DONG, N. Behavior of inclusions with weak adhesion to strip matrix during rolling using FEM. Journal of Materials Processing Technology, v. 209, p. 4274-4280, 2009. 